\title{
The Time for Chronotherapy in Radiation Oncology
}

\author{
Luis Bermúdez-Guzmán ${ }^{1 \dagger}$, Alejandro Blanco-Saborio ${ }^{1}$, Juliana Ramírez-Zamora ${ }^{1}$ \\ and Eduardo Lovo ${ }^{2 *}$
}

${ }^{1}$ Robotic Radiosurgery Center, International Cancer Center, San José, Costa Rica, ${ }^{2}$ International Cancer Center, Diagnostic Hospital, San Salvador, El Salvador

OPEN ACCESS

Edited by:

Dörthe Schaue,

UCLA David Geffen

School of Medicine,

United States

Reviewed by:

Isaac Kirubakaran Sundar,

University of Kansas

Medical Center,

United States

Nicole M. Kettner,

University of Texas MD

Anderson Cancer Center.

United States

*Correspondence:

Eduardo Lovo

elovo@centrodecancer.com.sv

tORCID ID:

Luis Bermúdez-Guzmán orcid.org/0000-0002-0749-4010

Specialty section:

This article was submitted to

Radiation Oncology,

a section of the journal

Frontiers in Oncology

Received: 29 March 2021

Accepted: 27 April 2021

Published: 11 May 2021

Citation:

Bermúdez-Guzmán L, Blanco-Saborío A, Ramírez-Zamora J and Lovo E (2021)

The Time for Chronotherapy

in Radiation Oncology.

Front. Oncol. 11:687672. doi: 10.3389/fonc.2021.687672
Five decades ago, Franz Halberg conceived the idea of a circadian-based therapy for cancer, given the differential tolerance to treatment derived from the intrinsic host rhythms. Nowadays, different experimental models have demonstrated that both the toxicity and efficacy of several anticancer drugs vary by more than $50 \%$ as a function of dosing time. Accordingly, it has been shown that chemotherapeutic regimens optimally timed with the circadian cycle have jointly improved patient outcomes both at the preclinical and clinical levels. Along with chemotherapy, radiation therapy is widely used for cancer treatment, but its effectiveness relies mainly on its ability to damage DNA. Notably, the DNA damage response including DNA repair, DNA damage checkpoints, and apoptosis is gated by the circadian clock. Thus, the therapeutic potential of circadian-based radiotherapy against cancer is mainly dependent upon the control that the molecular clock exerts on DNA repair enzymes across the cell cycle. Unfortunately, the time of treatment administration is not usually considered in clinical practice as it varies along the daytime working hours. Currently, only a few studies have evaluated whether the timing of radiotherapy affects the treatment outcome. Several of these studies show that it is possible to reduce the toxicity of the treatment if it is applied at a specific time range, although with some inconsistencies. In this Perspective, we review the main advances in the field of chronoradiotherapy, the possible causes of the inconsistencies observed in the studies so far and provide some recommendations for future trials.

Keywords: chronobiology, circadian cycle, radiotherapy, radiobiology, cell cycle, DNA repair

\section{INTRODUCTION}

The Nobel Prize in Physiology or Medicine 2017 was awarded jointly to Jeffrey C. Hall, Michael Rosbash and Michael W. Young for their work on the molecular mechanisms controlling the circadian rhythms $(1,2)$. The term circadian is derived from the Latin circa diem which means "around a day" and was coined by the pioneer physician Franz Halberg (3). Thus, circadian rhythms are daily cycles that control physiological processes at the transcriptional level through networks of genes that oscillate in this 24-hour fashion (4). The circadian transcriptional machinery consists of two transcription factors, CLOCK and BMAL1 (the activators) that heterodimerize and bind to the E-Box sequences of the promoters of $\sim 10-15 \%$ of our genes to direct their rhythmic transcription $(5,6)$. This transcriptional activity peaks during the day but is inhibited at night by the 
proteins period (PER) and cryptochrome (CRY) (the repressors) (5). Additionally, several kinases and phosphatases regulate the phosphorylation of both activators and repressors, controlling the localization and stability of these integral clock proteins (6).

The central circadian clock, the circadian pacemaker, is found in the hypothalamic suprachiasmatic nucleus (SCN) (7) which exerts control over several aspects of human physiology, including metabolism and sleep regulation. In addition, the SCN is also responsible for storing seasonal day-length information (8), allowing our circadian clock to adapt to seasonal changes in the natural light-dark cycle (9). Mechanistically, the SCN receives information about the time of day through light detected by ganglion cells of the retina and transmitted through the retinohypothalamic tract (RHT). Consequently, the daily patterns of physiology and behavior can be severely altered in blind people due to the lack of photic entrainment. In fact, more than $50 \%$ of blind people who lack a conscious perception of light cannot synchronize to the 24-hours day (10).

The phase of the circadian clock (the stage in the cycle relative to external time) is determined by environmental cues named "zeitgebers" (such as light, temperature and food intake). The strength of the stimulus and the circadian phase during which it is applied will determine the response of the circadian clock to zeitgebers (11). Notably, these stimulus can function as "synchronizers" which in turn can reset the body's circadian clock and place all cells in the same phase of circadian oscillation, in a process called circadian rhythm synchronization (12). Internal representations of the time of day are transmitted to the rest of the body through hormones, the sympathetic/ parasympathetic nervous system, and the core body temperature (11). Thus, the central pacemaker can drive peripheral clock rhythms that are under the control of endogenous regulatory factors from the SCN (12). For instance, the SCN ensures that the pineal gland rhythmically produces melatonin (peak levels at night) to promote sleep in diurnal animals. Likewise, the SCN drives the release of adrenocorticotropic hormone (ACTH), which in turn causes an increase in corticosterone release from the adrenal gland in the mornings (13). Figure 1 summarizes the core components of the circadian clock at the molecular and systemic levels.

\section{CIRCADIAN CYCLE IN CANCER}

\section{Circadian Cycle and Cancer Susceptibility}

More than a decade ago, the International Agency for Research on Cancer (IARC) listed shift work (day/night) as a probable human carcinogen (classified in Group 2A) (14). Nowadays, it is well known that the disruption of the circadian cycle is associated with a higher incidence of different types of cancer (15). Although the association has been established in several epidemiological studies, the causes and factors related to this interruption remain unclear. However, a recent study reported that circadian dysregulation of DNA repair may increase DNA damage and predispose to elevated cancer risk in night shift workers (16). Even when some studies provide compelling information on association between the circadian cycle and cancer, it is not yet clear whether there is any specificity for different types of cancer $(17,18)$.

Some studies have already demonstrated that polymorphisms in the circadian clock genes are associated with higher cancer risk. For instance, one study demonstrated that several SNPs in different core circadian genes were associated with susceptibility to prostate cancer (19). Similarly, NPAS2 has been associated with an increased predisposition to sarcoma and breast cancer risk $(20,21)$. Another study showed a relationship between an increased breast cancer risk and polymorphisms in CRY2, PER2 and PER1 (22). Polymorphism in NPAS2, PER1 and PER2 have also been associated to gastric cancer predisposition (23). Three CRY2 SNPs were also found to be significantly associated with risk of non-Hodgkin's lymphoma (24). A polymorphism in the CLOCK1 gene was shown to increase the risk for colorectal cancer development (25). Besides these associations related to cancer susceptibility, the role of the circadian clock in cancer can be analyzed from three different perspectives: 1) the circadian clock disruption as a carcinogenic agent, 2) the circadian control of carcinogenesis and 3) the circadian rhythm as a guide to administer anticancer treatment (26). We will focus on this last aspect for the purpose of this work.

\section{Circadian Cycle in Cancer Treatment}

Five decades ago, Franz Halberg conceived the idea of a circadian-based therapy (chronotherapy) for cancer, given the differential tolerance to treatment derived from the intrinsic host rhythms (27). Since that moment, the idea behind chronobiology has been relevant to understand how time-related events shape our daily biological responses including response to anticancer treatment (28). Different experimental models have demonstrated that both the toxicity and efficacy of over 30 anticancer agents vary by more than $50 \%$ as a function of dosing time (29). The rationale for this relies on the fact that time-dependent efficacy of treatments may vary according to three general aspects: 1) the mechanism of action, 2) the pharmacokinetics/metabolism and 3) the variable toxicity depending on circadian rhythms (30). Accordingly, it has been shown that regimens optimally timed with the circadian cycle have jointly improved patient outcomes in terms of tolerance and efficacy of chemotherapeutic treatments, both at the preclinical and clinical level $(31,32)$. One of the best examples of this is the use of chronochemotherapy for gynecological and genitourinary cancers (33).

\section{CHRONOTHERAPY IN RADIATION ONCOLOGY}

\section{Preclinical Studies}

Human cells undergo daily cycles in gene expression, protein levels and enzymatic activity. Accordingly, circadian rhythmdependent cell cycle progression can produce variations in the response to radiological treatment as cells are most radiosensitive in the G2-M phase (34). Radiation Therapy (RT) is widely used 


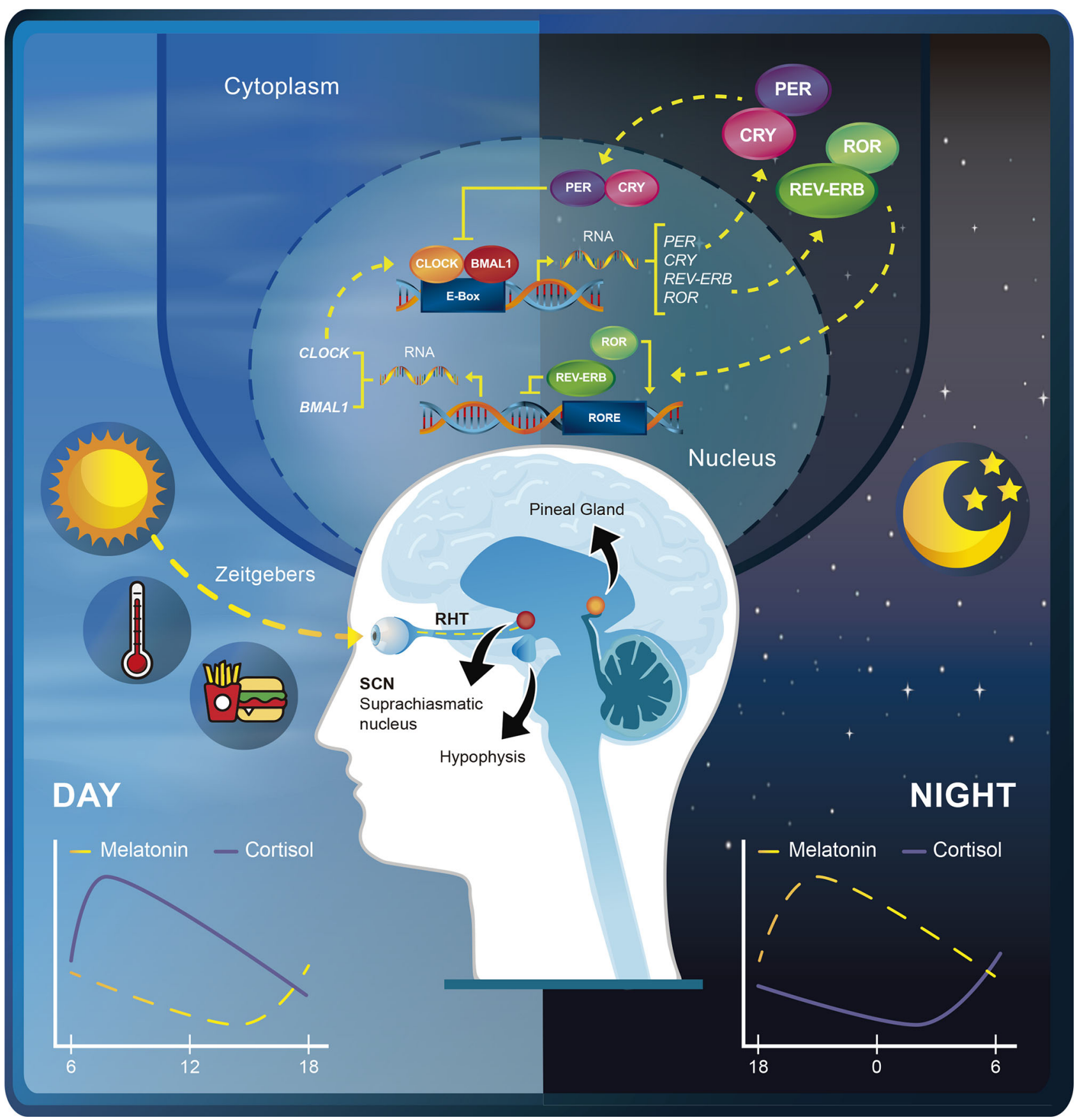

FIGURE 1 | Schematic depiction of the rhythmic expression of the circadian transcriptional machinery. The transcriptional activity of CLOCK-BMAL1 peaks during the day but is inhibited at night by the transcription repressors PER-CRY. RORs activate the transcription of BMAL1 and CLOCK, whereas REV-ERBs repress BMAL1 and CLOCK through retinoic acid-related orphan receptor response element (RORE) binding. Zeitgebers such as light, temperature, and food synchronize the phase of the internal circadian clock relative to the external time. Light is detected by ganglion cells of the retina and transmitted through the retinohypothalamic tract $(\mathrm{RHT})$ to the suprachiasmatic nucleus (SNC). The SCN in turns ensures that the pineal gland rhythmically produces melatonin and drives the release of adrenocorticotropic hormone (ACTH) from the hypophysis. This promotes daily peaks of melatonin and cortisol release at different times of the day.

for cancer treatment, but its effectiveness relies mainly on its ability to damage DNA. In fact, radioresistance partly emerges because of efficient and redundant DNA repair capacities (35). It is also known that a two-way connection between DNA repair and cell cycle ensures genomic integrity within cells (36). Notably, the DNA damage response (DRR) including DNA repair, DNA damage checkpoints, and apoptosis is also gated by the circadian clock (37). Thus, the therapeutic potential of 
circadian-based radiotherapy against cancer is mainly dependent upon the control that the molecular clock exerts on DNA repair enzymes across the cell cycle. In mammalian cells, the ATM/ Chk2 signaling pathway is activated by double-strand breaks that are mainly induced by ionizing radiation (IR) (38). The circadian protein PER1 participates in this ATM-Chk2 signaling pathway in response to IR by directly interacting with both proteins $(37,39)$. Consequently, PER1 is upregulated by radiation and is required for radiation-induced apoptosis (39). Table 1 summarizes some the most important preclinical studies addressing the effect of the circadian clock on DDR and the toxicity and response to radiation therapy. A better understanding of the control that these clock proteins exert on DRR at the molecular level will provide further insights at the clinical level to develop accurate circadian-based radiotherapy regimes.

\section{Clinical Studies}

In clinical practice, the time of treatment administration is not usually considered and varies along the daytime working hours. Currently, only a few studies have evaluated whether the timing of radiotherapy (chronoradiotherapy) affects the treatment outcome. Some of these studies have determined that it is possible to reduce the toxicity of radiotherapy if it is administered at a specific time, although this is dependent on the type of cancer (47). Despite this, there are inconsistencies in the literature regarding the treatment outcomes of this approach. However, we consider that part of the inconsistencies derives from important differences in methodology. Additionally, it is well known that the circadian time-dependent interaction between host, cancer and treatment outcome is further impacted by inter-individual differences and clock genes polymorphisms (29).

To date, three studies (47-49) have compiled the conclusions of the main prospective and retrospective studies that have evaluated the effect of time of day with respect to treatment outcome after radiotherapy. From these studies, only three are randomized prospective trials. Most of these studies used different sources of irradiation, used different time intervals for morning/afternoon groups, used symptoms as the primary endpoint, and only few used consensus guidelines to evaluate treatment outcome. This makes it difficult to present definitive claims about the effect of chronoradiotherapy. Therefore, we will highlight the most remarkable aspects of these studies that can be useful for future trials.

The three prospective randomized studies $(n=611)$ analyzed the effect of time of day on the prevalence of mucositis after radiotherapy delivered in the morning and afternoon. Two of the studies looked at the severity and prevalence of radiationinduced oral mucositis in head and neck cancer but found no clear difference between the two groups $(50,51)$. However, a consistent trend between both studies was that patients treated in the afternoon exhibited a more rapid progression in the grade of mucositis and the median time to development of grade III/IV mucositis was significantly longer in morning patients $(50,51)$. What is remarkable from one of these trials (51) is that the study was based on the previous demonstration of a circadian rhythm in the human oral mucosa cell cycle, with most cells in the G1 phase in the morning and $\mathrm{M}$ phase at night. Interestingly, a recent retrospective study $(n=617)$ evaluating the impact of delivery daytime and seasonality of radiotherapy for head and neck cancer found higher acute toxicity for radiotherapy

TABLE 1 | Preclinical studies on the role of the circadian clock in DNA repair and radiotherapy.

\begin{tabular}{|c|c|c|c|c|}
\hline $\begin{array}{l}\text { Type of } \\
\text { study }\end{array}$ & Model & Hypothesis & Main findings & Reference \\
\hline In vitro & $\begin{array}{l}\text { Mouse } \\
\text { splenocytes }\end{array}$ & $\begin{array}{l}\text { Day and night variations influence } \\
\text { IR-induced DNA damage repair }\end{array}$ & $\begin{array}{l}\text { IR-induced DNA damage is more efficiently repaired during the light phase due to day- } \\
\text { time-dependent expression levels of clock-associated genes (especially DNA repair genes). }\end{array}$ & $(40)$ \\
\hline $\begin{array}{l}\text { In vitro } \\
\text { In vivo }\end{array}$ & $\begin{array}{l}\text { Hair follicles/ } \\
\text { Transgenic } \\
\text { mice }\end{array}$ & $\begin{array}{l}\text { The circadian clock influences the } \\
\text { mitotic activity and regeneration of } \\
\text { anagen hair follicles. }\end{array}$ & $\begin{array}{l}\text { Hairs grow faster in the morning than in the evening leading to a remarkable time-of-day- } \\
\text { dependent sensitivity of growing hair follicles to genotoxic stress. Same doses of } \gamma \text { - } \\
\text { radiation caused dramatic hair loss in WT mice when administered in the morning, } \\
\text { compared with the evening, when hair loss is minimal. }\end{array}$ & $(41)$ \\
\hline In vivo & $\begin{array}{l}\text { Xenografted } \\
\text { BALB/c (nu/ } \\
\text { nu) mice }\end{array}$ & $\begin{array}{l}\text { Topotecan (TPT) and RT can be } \\
\text { chronomodulated to get better } \\
\text { results in a model of human } \\
\text { nasopharyngeal carcinoma. }\end{array}$ & $\begin{array}{l}\text { The TPT-RT combination was more effective than TPT or RT as single agents. The TPT-RT } \\
\text { combination at } 15 \text { hours after light onset (HALO) was best and TPT-RT at } 3 \text { HALO was } \\
\text { worst. }\end{array}$ & (42) \\
\hline In vivo & $\begin{array}{l}\text { mPer2-/- } \\
\text { mice }\end{array}$ & $\begin{array}{l}\text { The mPer2 gene functions in tumor } \\
\text { suppression by regulating DNA } \\
\text { damage-responsive pathways. }\end{array}$ & $\begin{array}{l}\text { mPer2-/- mice show a neoplastic growth phenotype and an increased sensitivity to } \gamma \text { - } \\
\text { radiation, manifested by premature hair graying, increased tumor occurrence, and reduced } \\
\text { apoptotic response in thymocytes. }\end{array}$ & (43) \\
\hline In vitro & $\begin{array}{l}\text { Human } \\
\text { fibroblasts }\end{array}$ & $\begin{array}{l}\text { The cellular response to DNA } \\
\text { damage is related to the } \\
\text { endogenous expression levels of } \\
\text { PER2. }\end{array}$ & $\begin{array}{l}\text { Clonogenic cell survival, double-strand break repair kinetics, and TP53 activation were } \\
\text { affected in irradiated cells with low endogenous PER2 protein levels (compared to high } \\
\text { levels). }\end{array}$ & (44) \\
\hline In vivo & $\begin{array}{l}\text { WT and } \\
\text { Per1/2 KO } \\
\text { Mice }\end{array}$ & $\begin{array}{l}\text { The circadian system plays } \\
\text { regulatory roles in minimizing the } \\
\text { IR-induced cardiotoxicity. }\end{array}$ & $\begin{array}{l}\text { Compared to control mice (day shift), circadian clock disruption either environmentally } \\
\text { (rotating shift) or genetically (Per } 1 / 2 \text { mutant) significantly exacerbated post-IR } \\
\text { cardiotoxicity. }\end{array}$ & (45) \\
\hline In vivo & $\begin{array}{l}\text { Sprague- } \\
\text { Dawley male } \\
\text { rats }\end{array}$ & $\begin{array}{l}\text { Per1 and Per2 can increase the } \\
\text { radiosensitivity of glioma. }\end{array}$ & $\begin{array}{l}\text { High expression of Per } 1 / 2 \text { was associated with increased sensitivity to } x \text {-irradiation only in } \\
\text { glioma tissue. The high expression of Per } 1 / 2 \text { can induce cell cycle arrest and increase } \\
\text { tumor sensitivity to x-rays through a p53-dependent mechanism. }\end{array}$ & (46) \\
\hline
\end{tabular}


delivered in dark seasonality (each year was divided into dark and light by the March and September equinoxes) (52).

The third prospective randomized study evaluated the prevalence of acute gastrointestinal mucositis in cervical cancer. Interestingly, contrary to what was observed in head and neck cancer, patients in the morning group exhibited a higher prevalence of grade III/IV mucositis than patients treated in the afternoon (53). However, we consider that the endpoint of this retrospective study should be addressed with the current management guidelines for cervical cancer using radiation therapy. Additionally, a different study found that RT in the morning reduces severe hematological toxicity in inoperable cervical cancer patients (using a very similar time range) (54). Taken together, two main aspects can be highlighted from these three prospective randomized studies: 1) all used the Radiation Therapy Oncology Group (RTOG) toxicity criteria and 2) the time range for the morning and afternoon groups was specific and more consistent (morning ranging from 8:00 to 11:00 and afternoon from 15:00 to 20:00).

Four retrospective studies $(n=840)$ evaluated the effect of chronoradiotherapy on non-small cell lung cancer brain metastases. Two studies found no correlation between time of day and overall survival or local control $(55,56)$. One study found a trend towards improved median and 2-year overall survival for morning group when a cut-off point of 11:42am was used (57). The last study found that the morning group experienced significantly improved 3-month local control, median overall survival and fewer CNS-related deaths (58). However, the influence of the small sample size on the results of this last study cannot be ruled out. The differences between these retrospective studies may be due to several factors, but we consider that the main drawback in terms of chronotherapy is using a specific time point to separate morning and afternoon groups. We believe that a better option is to define a specific time interval for morning and afternoon cohorts with a significant gap of time between both groups. This would be more appropriate considering that the intention is to translate the biological effects of the circadian cycle at the cellular level on the therapeutic response. Another retrospective study $(\mathrm{n}=755)$ including patients (median age $=66$ ) with multiple brain metastases, found that the time of whole-brain radiotherapy delivery for brain metastases was significantly related to overall survival upon univariate analyzes in females only (59). However, in this study the patients were grouped according to the percentage of sessions (i.e., $100 \%, 80 \%, 60 \%$ ) that they received in one specific time frame. Additionally, patients with many types of primary cancer were included. In fact, when it comes to brain metastases, it has been shown that treatment response, clinical outcomes, and quality of life, are influenced by certain prognostic factors (like number of tumor lesions, functional status, age, comorbidities, etc.) $(60,61)$. Following this idea and based on these retrospective studies, we recommended to have a cohort of patients as homogeneous as possible when analyzing the impact of chronoradiotherapy on patient outcomes.

For primary brain cancer, few studies have addressed the utility of chronoradiotherapy. One study demonstrated that time-of-day-dependent sensitivity to radiation was different in normal and cancerous cell lines of the central nervous system based on PER2 expression (48). Both rat and human GBM cell lines were more affected by radiation at different times compared to SCN cells, suggesting that timing of radiation could be optimized to improve detrimental effects on healthy tissue, while still providing effective antitumoral doses. A retrospective study $(n=109)$ evaluating the impact on chronoradiotherapy in high grade gliomas found no difference in overall survival and progression free survival for patients treated in the morning or afternoon (62). However, in terms of timing, patients were included in the morning group if $\geq 50 \%$ of fractions were delivered before 12:00 h.

Two different studies $(\mathrm{n}=1275)$ analyzing toxicity associated with breast cancer radiotherapy found opposite results. The first showed a higher incidence of worse reactions in the morning (63) (in both retrospective and prospective cohorts) while the other reported a higher incidence of grade 2 skin reactions in the afternoon (after 15:00 h) (64). Notably, the clinicopathologic characteristics were relatively well balanced between the treatment groups in the latter study. Additionally, it is also remarkable that the former study showed that an increased late effect in the group receiving morning radiotherapy was associated with carriage of a variable number tandem repeat (4/4 genotype) in PER3 and a SNP (rs131116075) in the NOCT gene (AA genotype) (63).

One retrospective study $(n=409)$ in patients undergoing definitive high-dose RT for prostate cancer (median 78 Gy) found that evening RT may lead to more gastrointestinal complications, especially in patients older than 70 years old (65). However, the specific time point to define daytime treatment (before $5 \mathrm{PM}$ ) is very broad in our opinion. Additionally, it should be considered that for prostate cancer, there must be an adequate patient preparation (rectum and bladder) to reduce the movement of the gland during or between sessions of radiotherapy as that may affect treatment outcome. Another study $(\mathrm{n}=168)$ in patients with localized prostate cancer found that lower urinary tract symptoms were significantly ameliorated in patients who received proton beam therapy in the morning (before 10:30 AM) (66).

A retrospective study $(n=155)$ in patients with locally advanced rectal cancer found that those who received the majority of their radiotherapy fractions after 12:00 pm were more likely to show a complete or moderate pathological response and improved nodal downstaging (67). Notably, less tumor response was reported in females when compared to males, but this may be caused by gender imbalance ( 45 females versus 110 males). Additionally, there was no defined time range, but patients were separated according to the percentage of fractions received after a specific time point (12:00 pm).

\section{DISCUSSION AND FUTURE DIRECTIONS}

Although the evidence so far indicates that chronoradiotherapy could represent a promising approach in clinical practice, some 
variables still need to be standardized to extend its use. Additionally, more basic research is needed to guide potential clinical trials in different types of cancer, especially those that rely more on radiological treatment. In the next section, we will discuss some aspects that must be either improved or taken into consideration for future chronoradiotherapy trials (Figure 2).

\section{Time of Treatment}

For most studies so far, there is a lack of consensus when defining a time range for morning and afternoon cohorts. Although we recognize that it might be difficult to reach this consensus, we suggest to define time ranges similar to the ones reported in the head and neck cancer retrospective studies $(50,51)$. Short periods of time for the morning (i.e., 8:00-10:00am) and afternoon (i.e., 16:00-18:00) groups would be useful to evaluate whether it is possible to capture significant biological differences derived from the circadian rhythm. Likewise, separating both groups by at least 4-6 h would allow the differences observed between groups to be attributed to the circadian cycle with greater certainty. We do not recommend using a specific time point to separate patients in the morning/afternoon arms. It can also be useful to analyze the existing evidence on the circadian rhythm dependent cell cycle progression of the tissue that is being irradiated to guide clinical trials. This approach was shown to be useful for head and neck cancer, where a circadian rhythm in the human oral mucosa cell cycle was demonstrated, leading to the hypothesis that morning radiotherapy would cause less oral mucositis (51).

A complementary approach could be to define the chronotype of the patients under study in prospective trials. The chronotype is a representation of the patient's circadian rhythm and refers to preferences for timing of sleep and

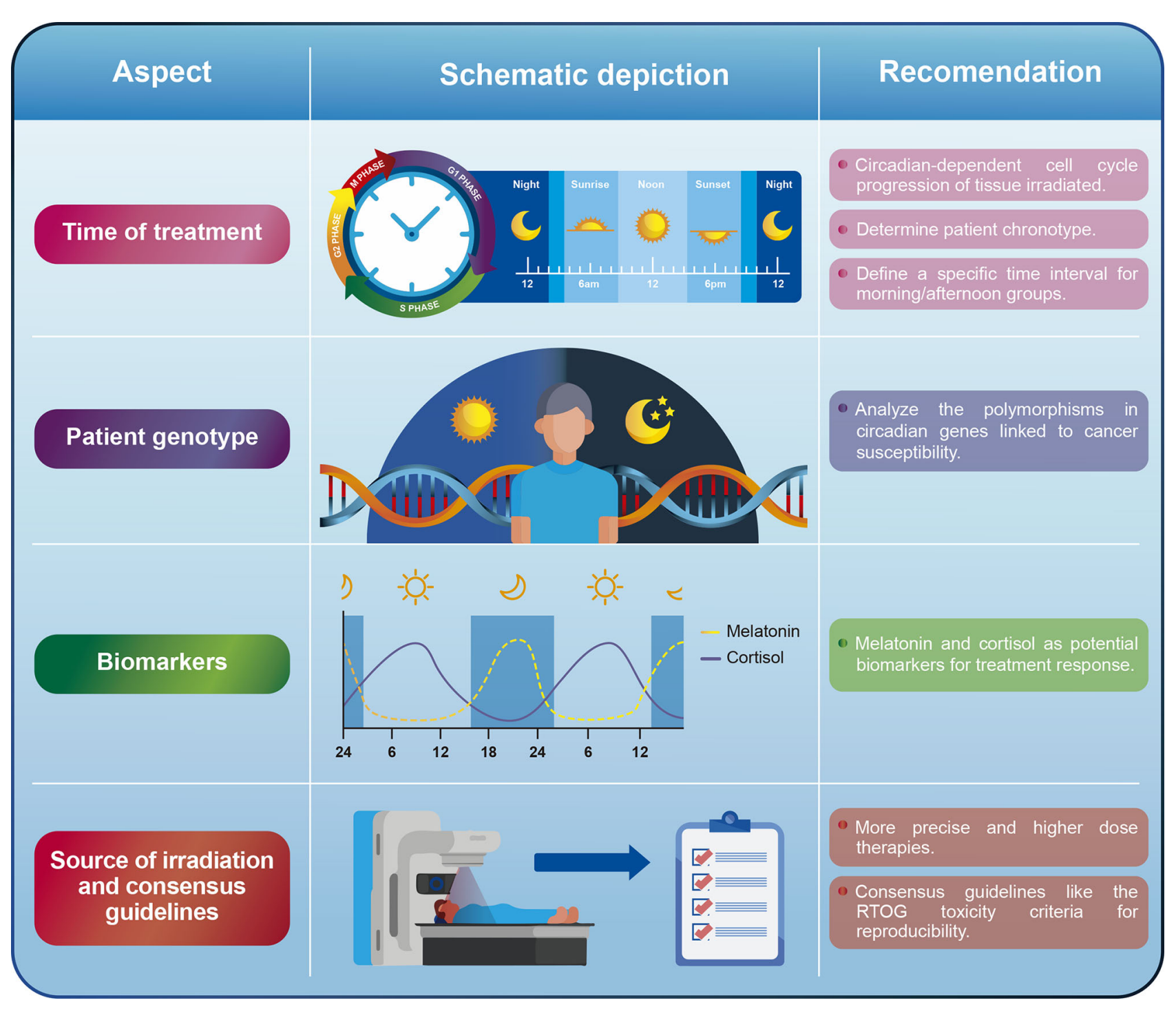

FIGURE 2 | General recommendations for some of the aspects that must be improved or addressed in chronoradiotherapy. 
wakefulness. Early-type subjects (commonly known as larks) naturally wake up and fall asleep earlier than late-type individuals (known as night owls) (68). Identifying patient's chronotypes can be done via different ways including survey, either by using the well-known Morningness-Eveningness Questionnaire (MEQ) (69) or the Munich ChronoType Questionnaire (MCTQ) (70). Determining the chronotype is important since the internal time is not the same between individuals as their endogenous circadian clocks have different phase relationships with respect to external clock time (71). None of the studies carried out so far evaluating the effect of chronoradiotherapy has determined the chronotype of the patients. In contrast, some studies have found a relationship between the patients' chronotype and chemotherapy-associated toxicity. For example, one study found that late chronotypes are associated with neoadjuvant chemotherapy-induced nausea and vomiting in women with breast cancer (72). For this reason, we encourage to carry out prospective trials that consider patients' chronotypes.

\section{Patient Genotype}

Different clock genes polymorphisms have been associated with cancer susceptibility, especially colorectal (25), breast (22), and gastric cancer (23). Although the involvement of these genes in different cellular pathways is known, little is known about their influence on the response to cancer treatment, especially in radiotherapy. Circadian clock PER proteins (PER1, PER2, and PER3) are important repressors of the transcriptional activity of the CLOCK/BMAL1 complex. Additionally, PER1 participates in the ATM-Chk2 signaling pathway in response to IR by directly interacting with both proteins $(37,39)$ as it is upregulated by radiation and required for radiation-induced apoptosis (39). So far, only one study evaluating chronoradiotherapy in breast cancer has shown that certain alleles of two circadian rhythm genes (PER3 and NOCT) predict worse outcome in the morning group (63). Although it may be somewhat difficult to incorporate into clinical practice, future trials should evaluate the polymorphisms of those clock genes that have been linked to cancer susceptibility and treatment response. Thus, when considering the genotype of patients, it could be determined which polymorphism are associated with a better or worse response to chronoradiotherapy.

\section{Biomarkers}

The variations in hormonal levels during the day are also closely linked to the circadian cycle. For example, serum cortisol shows low values at night, a peak early in the morning (7:00-8:00am) and decreasing values during the day (73). On the other hand, serum melatonin presents high values at night and extremely low values during the day (74). It has been shown that stress hormones can increase DNA damage and alter transcriptional regulation of the cell cycle (75). For instance, long exposures (24 h) in dose-response experiments with norepinephrine or epinephrine induced significant increases in DNA damage in treated cells compared to that of untreated cells (76). Likewise, acute exposure to cortisol and norepinephrine significantly increased levels of ROS/RNS and DNA damage in breast cancer cell lines (77). One study in patients with metastatic breast cancer $(n=104)$ found that the variability in the diurnal cortisol rhythm is a significant predictor of survival time (78).

On the other hand, it has been demonstrated that melatonin exerts some anticancer activity especially mediated by interfering with various cancer hallmarks (79). It is well known that melatonin modulates DNA damage response and DNA repair pathways (80). For instance, melatonin induces phosphorylation of p53 inhibiting cell proliferation, preventing DNA damage accumulation of both normal and transformed cells (81). Additionally, melatonin showed to enhance the effects of radiotherapy (82), by sensitizing cancer cells to ionizing radiation $(83,84)$. Likewise, pre-treatment with melatonin was also shown to ameliorate harmful effects of irradiation-induced oxidative damage in rat peripheral blood (85). Notably, a metaanalysis of human trials using melatonin as adjunct treatment concurrent with chemotherapy or radiotherapy found that melatonin significantly improved tumor remission, 1-year survival, and alleviation of radiochemotherapy-related side effects across different types of cancer (86). Another study $(n=30)$ showed that survival at 1 year was significantly higher in patients treated with RT plus melatonin than in those receiving RT alone (87). Additionally, RT or steroid therapyrelated toxicities were lower in patients concomitantly treated with melatonin. Taken together, these hormones could be used as response or prognostic markers for chronoradiotherapy since they have been shown to play an important role in DNA repair and response to radiation therapy. However, none of the studies carried out so far evaluating the effect of chronoradiotherapy have also measured the serological levels of these hormones to assess whether they can serve as biomarkers correlating to treatment response.

\section{Clock-Modulating Compounds}

Many studies have identified several small-molecule agonists and antagonists for clock-related proteins, especially for CRY, ROR and REV-ERB $(88,89)$. For instance, a recent study showed that that two agonists of REV-ERBs (SR9009 \& SR9011) are lethal to cancer cells and oncogene-induced senescent cells but have no effect on the viability of normal cells (90). Another study identified a small molecule called KL001 that specifically interacts with CRY (91). This molecule prevented proteasomal degradation of CRY, resulting in lengthening of the circadian period. Other studies have employed high-throughput chemical screening to identify novel clock-modulating compounds. For example, from a screening of over 1,000 small molecules using an FDA-approved drug library and the International Drug Collection, $5 \%$ of the drugs screened altered the circadian period (92). Other studies using high-throughput screening and circadian luciferase reporter assays have found several compounds targeting the circadian clock out of thousands of molecules (93-95). Future preclinical trials evaluating the effect of chronoradiotherapy in different types of cancer should consider the use of circadian-modulating compounds to prove their potential as adjuvant therapy. Perhaps in the future, clinical trials will be able to optimize the effects of circadian-based radiotherapy with the use of these modulating compounds. 


\section{Source of Irradiation and Consensus Guidelines}

Although it could be considered that different irradiation sources might not have a significant impact on chronoradiotherapy, we suggest that new trials should evaluate the use of more precise and higher-dose therapies as optimal doses can be directed to the tumor without causing greater toxicity to adjacent organs. In fact, most studies to date have evaluated the effect of chronoradiotherapy on the toxicity generated by the treatment in the surrounding healthy tissue but few studies have found a direct effect on local tumor control. We believe that the use of Stereotactic Radiosurgery (SRS) (a form of radiation therapy that focuses a high dose of energy on a small area of the body) could be an interesting approach to evaluate chronoradiotherapy. For instance, it has been shown that SRS using Cyberknife generates better local tumor control in some types of cancer (96-99). We consider that the high doses and high precision provided by SRS could be a promising approach to assess tumor response to chronoradiotherapy given the fact that the main target of radiation will be the tumor tissue and not the surrounding tissue. In addition, using SRS ensures shorter treatment schedules (1-2 weeks versus 4-8 weeks or more), reducing the possible effects that other variables apart from timing have on the treatment outcome.

Another important aspect that must be considered is the consensus guidelines used to assess the toxicity following radiation therapy. Only few studies evaluating the effect of chronoradiotherapy have used consensus guidelines such as the toxicity criteria of the Radiation Therapy Oncology Group (RTOG) (100) and The Response Evaluation Criteria in Solid Tumors (RECIST) (101). Future trials should seek to use these or other recognized guidelines in order to make the results obtained between studies more comparable.

\section{CONCLUSION}

Although we are far from having some general guidelines, chronoradiotherapy represents an approach that deserves to be

\section{REFERENCES}

1. Zehring WA, Wheeler DA, Reddy P, Konopka RJ, Kyriacou CP, Rosbash M, et al. P-Element Transformation With Period Locus DNA Restores Rhythmicity to Mutant, Arrhythmic Drosophila Melanogaster. Cell (1984) 39:369-76. doi: 10.1016/0092-8674(84)90015-1

2. Vosshall L, Price J, Sehgal A, Saez L, Young M. Block in Nuclear Localization of Period Protein by a Second Clock Mutation, Timeless. Science (1994) 263:1606-9. doi: 10.1126/science.8128247

3. Lee JY, Lee MS, Lee JS, Halberg FE, Halberg J, Schwartzkopff O, et al. A Tribute to Franz Halberg, MD. Hypertension (2015) 66:1090-2. doi: 10.1161/ HYPERTENSIONAHA.115.06338

4. Rijo-Ferreira F, Takahashi JS. Genomics of Circadian Rhythms in Health and Disease. Genome Med (2019) 11:82. doi: 10.1186/s13073-019-0704-0

5. Masri S, Sassone-Corsi P. The Emerging Link Between Cancer, Metabolism, and Circadian Rhythms. Nat Med (2018) 24:1795-803. doi: 10.1038/s41591-018-0271-8

6. Partch CL, Green CB, Takahashi JS. Molecular Architecture of the Mammalian Circadian Clock. Trends Cell Biol (2014) 24:90-9. doi: 10.1016/ j.tcb.2013.07.002 studied further given the cumulative evidence on the reduced toxicity of circadian-based radiotherapy. However, although the trials carried out so far have shown that it is possible to reduce the toxicity associated with radiotherapy in a time-of-daydependent manner, many inconsistencies persist due to the lack of guidelines that standardize this practice. We hope that this perspective will provide some new insights and recommendations that guide future clinical trials evaluating the impact of chronoradiotherapy not only in terms of toxicity but also tumor control in different types of cancer.

\section{DATA AVAILABILITY STATEMENT}

The original contributions presented in the study are included in the article/supplementary material. Further inquiries can be directed to the corresponding author.

\section{AUTHOR CONTRIBUTIONS}

LB-G. conceived the idea and wrote the manuscript with input from all authors. AB-S revised the manuscript. JR-Z revised the manuscript. EL revised the manuscript and managed the project. All authors contributed to the article and approved the submitted version.

\section{FUNDING}

This work was funded by the International Cancer Center, San José, Costa Rica/San Salvador, El Salvador.

\section{ACKNOWLEDGMENTS}

We thank Gabriel Jimenez-Huezo for the graphic design of the pictures in this paper.

7. Schibler U, Sassone-Corsi P. A Web of Circadian Pacemakers. Cell (2002) 111:919-22. doi: 10.1016/S0092-8674(02)01225-4

8. Hannay KM, Forger DB, Booth V. Seasonality and Light Phase-Resetting in the Mammalian Circadian Rhythm. Sci Rep (2020) 10:19506. doi: 10.1038/ s41598-020-74002-2

9. Stothard ER, McHill AW, Depner CM, Birks BR, Moehlman TM, Ritchie $\mathrm{HK}$, et al. Circadian Entrainment to the Natural Light-Dark Cycle Across Seasons and the Weekend. Curr Biol (2017) 27:508-13. doi: 10.1016/ j.cub.2016.12.041

10. Allen AE. Circadian Rhythms in the Blind. Curr Opin Behav Sci (2019) 30:73-9. doi: 10.1016/j.cobeha.2019.06.003

11. Patke A, Young MW, Axelrod S. Molecular Mechanisms and Physiological Importance of Circadian Rhythms. Nat Rev Mol Cell Biol (2020) 21:67-84. doi: 10.1038/s41580-019-0179-2

12. Xie Y, Tang Q, Chen G, Xie M, Yu S, Zhao J, et al. New Insights Into the Circadian Rhythm and Its Related Diseases. Front Physiol (2019) 10:682. doi: 10.3389/fphys.2019.00682

13. Panda S. Circadian Physiology of Metabolism. Science (2016) 354:1008-15 doi: 10.1126/science.aah4967 
14. Straif K, Baan R, Grosse Y, Secretan B, Ghissassi FE, Bouvard V, et al. Carcinogenicity of Shift-Work, Painting, and Fire-Fighting. Lancet Oncol (2007) 8:1065-6. doi: 10.1016/S1470-2045(07)70373-X

15. Shafi AA, Knudsen KE. Cancer and the Circadian Clock. Cancer Res (2019) 79:3806-14. doi: 10.1158/0008-5472.CAN-19-0566

16. Koritala BSC, Porter KI, Arshad OA, Gajula RP, Mitchell HD, Arman T, et al. Night Shift Schedule Causes Circadian Dysregulation of DNA Repair Genes and Elevated DNA Damage in Humans. J Pineal Res (2021) 70(3): e12726. doi: 10.1111/jpi.12726

17. Lee S, Donehower LA, Herron AJ, Moore DD, Fu L. Disrupting Circadian Homeostasis of Sympathetic Signaling Promotes Tumor Development in Mice. PloS One (2010) 5:e10995. doi: 10.1371/journal.pone.0010995

18. Papagiannakopoulos T, Bauer MR, Davidson SM, Heimann M, Subbaraj L, Bhutkar A, et al. Circadian Rhythm Disruption Promotes Lung Tumorigenesis. Cell Metab (2016) 24:324-31. doi: 10.1016/j.cmet.2016.07.001

19. Zhu Y, Stevens RG, Hoffman AE, FitzGerald LM, Kwon EM, Ostrander EA, et al. Testing the Circadian Gene Hypothesis in Prostate Cancer: A Population-Based Case-Control Study. Cancer Res (2009) 69:9315-22. doi: 10.1158/0008-5472.CAN-09-0648

20. Benna C, Rajendran S, Spiro G, Tropea S, Del Fiore P, Rossi CR, et al. Associations of Clock Genes Polymorphisms With Soft Tissue Sarcoma Susceptibility and Prognosis. J Transl Med (2018) 16:338. doi: 10.1186/ s12967-018-1715-0

21. Zhu Y, Stevens RG, Leaderer D, Hoffman A, Holford T, Zhang Y, et al. NonSynonymous Polymorphisms in the Circadian Gene NPAS2 and Breast Cancer Risk. Breast Cancer Res Treat (2008) 107:421-5. doi: 10.1007/s10549007-9565-0

22. Lesicka M, Jabłońska E, Wieczorek E, Pepłońska B, Gromadzińska J, Seroczyńska B, et al. Circadian Gene Polymorphisms Associated With Breast Cancer Susceptibility. Int J Mol Sci (2019) 20:5704. doi: 10.3390/ ijms20225704

23. Rajendran S, Benna C, Marchet A, Nitti D, Mocellin S. Germline Polymorphisms of Circadian Genes and Gastric Cancer Predisposition. Cancer Commun (2020) 40:234-8. doi: 10.1002/cac2.12008

24. Hoffman AE, Zheng T, Stevens RG, Ba Y, Zhang Y, Leaderer D, et al. ClockCancer Connection in non-Hodgkin's Lymphoma: A Genetic Association Study and Pathway Analysis of the Circadian Gene Cryptochrome 2. Cancer Res (2009) 69:3605-13. doi: 10.1158/0008-5472.CAN-08-4572

25. Karantanos T, Theodoropoulos G, Gazouli M, Vaiopoulou A, Karantanou C, Stravopodis DJ, et al. Association of the Clock Genes Polymorphisms With Colorectal Cancer Susceptibility: Clock Gene Polymorphisms and CRC. J Surg Oncol (2013) 108:563-7. doi: 10.1002/jso.23434

26. Sancar A, Lindsey-Boltz LA, Gaddameedhi S, Selby CP, Ye R, Chiou Y-Y, et al. Circadian Clock, Cancer, and Chemotherapy. Biochemistry (2015) 54:110-23. doi: 10.1021/bi5007354

27. Halberg F, Haus E, Cardoso SS, Scheving LE, Kühl JFW, Shiotsuka R, et al. Toward a Chronotherapy of Neoplasia: Tolerance of Treatment Depends Upon Host Rhythms. Experientia (1973) 29:909-34. doi: 10.1007/ BF01930381

28. Kraft M, Martin RJ. Chronobiology and Chronotherapy in Medicine. Disease-a-Month (1995) 41:506-75. doi: 10.1016/S0011-5029(95)90036-5

29. Lévi F, Focan C, Karaboué A, de la Valette V, Focan-Henrard D, Baron B, et al. Implications of Circadian Clocks for the Rhythmic Delivery of Cancer Therapeutics. Adv Drug Deliv Rev (2007) 59:1015-35. doi: 10.1016/ j.addr.2006.11.001

30. Sancar A, Van Gelder RN. Clocks, Cancer, and Chronochemotherapy. Science (2021) 371:eabb0738. doi: 10.1126/science.abb0738

31. Zhang Y, Lévi F, Chang Y. Chronotherapy With Defective Circadian Clock? Aging (2018) 10:520-1. doi: 10.18632/aging.101430

32. Dallmann R, Okyar A, Lévi F. Dosing-Time Makes the Poison: Circadian Regulation and Pharmacotherapy. Trends Mol Med (2016) 22:430-45. doi: 10.1016/j.molmed.2016.03.004

33. Kobayashi M, Wood PA, Hrushesky WJM. Circadian Chemotherapy for Gynecological and Genitourinary Cancers. Chronobiol Int (2002) 19:237-51. doi: 10.1081/CBI-120002600

34. Pawlik TM, Keyomarsi K. Role of Cell Cycle in Mediating Sensitivity to Radiotherapy. Int J Radiat Oncol Biol Phys (2004) 59:928-42. doi: 10.1016/ j.ijrobp.2004.03.005
35. Biau J, Chautard E, Verrelle P, Dutreix M. Altering DNA Repair to Improve Radiation Therapy: Specific and Multiple Pathway Targeting. Front Oncol (2019) 9:1009. doi: 10.3389/fonc.2019.01009

36. Hustedt N, Durocher D. The Control of DNA Repair by the Cell Cycle. Nat Cell Biol (2017) 19:1-9. doi: 10.1038/ncb3452

37. Sancar A, Lindsey-Boltz LA, Kang T-H, Reardon JT, Lee JH, Ozturk N. Circadian Clock Control of the Cellular Response to DNA Damage. FEBS Lett (2010) 584:2618-25. doi: 10.1016/j.febslet.2010.03.017

38. Li J, Stern DF. DNA Damage Regulates Chk2 Association With Chromatin. J Biol Chem (2005) 280:37948-56. doi: 10.1074/jbc.M509299200

39. Gery S, Komatsu N, Baldjyan L, Yu A, Koo D, Koeffler HP. The Circadian Gene Perl Plays an Important Role in Cell Growth and DNA Damage Control in Human Cancer Cells. Mol Cell (2006) 22:375-82. doi: 10.1016/ j.molcel.2006.03.038

40. Palombo P, Moreno-Villanueva M, Mangerich A. Day and Night Variations in the Repair of Ionizing-Radiation-Induced DNA Damage in Mouse Splenocytes. DNA Repair (2015) 28:37-47. doi: 10.1016/j.dnarep.2015.02.002

41. Plikus MV, Vollmers C, de la Cruz D, Chaix A, Ramos R, Panda S, et al. Local Circadian Clock Gates Cell Cycle Progression of Transient Amplifying Cells During Regenerative Hair Cycling. Proc Natl Acad Sci USA (2013) 110: E2106-15. doi: 10.1073/pnas.1215935110

42. Zhang Y, Chen X, Ren P, Su Z, Cao H, Zhou J, et al. Synergistic Effect of Combination Topotecan and Chronomodulated Radiation Therapy on Xenografted Human Nasopharyngeal Carcinoma. Int J Radiat Oncol Biol Phys (2013) 87:356-62. doi: 10.1016/j.ijrobp.2013.05.047

43. Fu L, Pelicano H, Liu J, Huang P, Lee CC. The Circadian Gene Period2 Plays an Important Role in Tumor Suppression and DNA Damage Response In Vivo. Cell (2002) 111:41-50. doi: 10.1016/S0092-8674(02)00961-3

44. Corrà S, Salvadori R, Bee L, Barbieri V, Mognato M. Analysis of DNAdamage Response to Ionizing Radiation in Serum-Shock Synchronized Human Fibroblasts. Cell Biol Toxicol (2017) 33:373-88. doi: 10.1007/ s10565-017-9394-9

45. Dakup PP, Porter KI, Gajula RP, Goel PN, Cheng Z, Gaddameedhi S. The Circadian Clock Protects Against Ionizing Radiation-Induced Cardiotoxicity. FASEB J (2020) 34:3347-58. doi: 10.1096/fj.201901850RR

46. Zhanfeng N, Yanhui L, Zhou F, Shaocai H, Guangxing L, Hechun X. Circadian Genes Per1 and Per2 Increase Radiosensitivity of Glioma In Vivo. Oncotarget (2015) 6:9951-8. doi: 10.18632/oncotarget.3179

47. Chan S, Rowbottom L, McDonald R, Bjarnason GA, Tsao M, Danjoux C, et al. Does the Time of Radiotherapy Affect Treatment Outcomes? A Review of the Literature. Clin Oncol (2017) 29:231-8. doi: 10.1016/j.clon.2016.12.005

48. Shuboni-Mulligan DD, Breton G, Smart D, Gilbert M, Armstrong TS. Radiation Chronotherapy-Clinical Impact of Treatment Time-of-Day: A Systematic Review. J Neurooncol (2019) 145:415-27. doi: 10.1007/s11060019-03332-7

49. Harper E, Talbot CJ. Is it Time to Change Radiotherapy: The Dawning of Chronoradiotherapy? Clin Oncol (2019) 31:326-35. doi: 10.1016/ j.clon.2019.02.010

50. Goyal M, Shukla P, Gupta D, Bisht SS, Dhawan A, Gupta S, et al. Oral Mucositis in Morning vs. Evening Irradiated Patients: A Randomised Prospective Study. Int J Radiat Biol (2009) 85:504-9. doi: 10.1080/ 09553000902883802

51. Bjarnason GA, MacKenzie RG, Nabid A, Hodson ID, El-Sayed S, Grimard L, et al. Comparison of Toxicity Associated With Early Morning Versus Late Afternoon Radiotherapy in Patients With Head-and-Neck Cancer: A Prospective Randomized Trial of the National Cancer Institute of Canada Clinical Trials Group (Hn3). Int J Radiat Oncol Biol Phys (2009) 73:166-72. doi: 10.1016/j.ijrobp.2008.07.009

52. Brolese EK, Cihoric N, Bojaxhiu B, Sermaxhaj B, Schanne DH, Mathier E, et al. The Impact of Delivery Daytime and Seasonality of Radiotherapy for Head and Neck Cancer on Toxicity Burden. Radiother Oncol (2021) 158:162-6. doi: 10.1016/j.radonc.2021.02.039

53. Shukla P, Gupta D, Bisht SS, Pant MC, Bhatt ML, Gupta R, et al. Circadian Variation in Radiation-Induced Intestinal Mucositis in Patients With Cervical Carcinoma. Cancer (2010) 116:2031-5. doi: 10.1002/cncr.24867

54. Chang L, Li L, Li W, Jiang M, Jv Y, Wang L, et al. Research on Radiotherapy At Different Times of the Day for Inoperable Cervical Cancer. CP (2016) 54:856-64. doi: 10.5414/CP202654 
55. Badiyan SN, Ferraro DJ, Yaddanapudi S, Drzymala RE, Lee AY, Silver SA, et al. Impact of Time of Day on Outcomes After Stereotactic Radiosurgery for non-Small Cell Lung Cancer Brain Metastases: SRS, NSCLC, and Treatment Time. Cancer (2013) 119:3563-9. doi: 10.1002/cncr.28237

56. Kabolizadeh P, Wegner R, Bernard M, Heron D, Mintz A, Burton S. The Effect of Treatment Time on Outcome in Non-small Cell Lung Cancer Brain Metastases Treated With Stereotactic Radiosurgery. Int J Radiat Oncol Biol Phys (2011) 81:S301. doi: 10.1016/j.ijrobp.2011.06.1784

57. Badiyan SN, Ferraro DJ, Yaddanapudi S, Drzymala RE, Lee AY, Simpson JR, et al. Ep-1293 Impact of Time of Day of Gamma Knife Radiosurgery on Survival for Non-Small Cell Lung Cancer Brain Metastases. Radiother Oncol (2012) 103:S491-2. doi: 10.1016/S0167-8140(12)71626-2

58. Rahn DA, Ray DK, Schlesinger DJ, Steiner L, Sheehan JP, O'Quigley JM, et al. Gamma Knife Radiosurgery for Brain Metastasis of Nonsmall Cell Lung Cancer: Is There a Difference in Outcome Between Morning and Afternoon Treatment? Cancer (2011) 117:414-20. doi: 10.1002/cncr.25423

59. Chan S, Rowbottom L, McDonald R, Zhang L, Bjarnason GA, Tsao M, et al. Could Time of Whole Brain Radiotherapy Delivery Impact Overall Survival in Patients With Multiple Brain Metastases? Ann Palliat Med (2016) 5:26779. doi: 10.21037/apm.2016.09.05

60. Hsiung C-Y, Leung SW, Wang C-J, Lo S-K, Chen H-C, Sun L-M, et al. The Prognostic Factors of Lung Cancer Patients With Brain Metastases Treated With Radiotherapy. J Neurooncol (1998) 36:71-7. doi: 10.1023/ A:1005775029983

61. Ren B, Zou L, Guo Q, Tian Y. Survival and Effective Prognostic Factors in Lung Cancer Patients With Brain Metastases Treated With Whole Brain Radiotherapy. Radiat Med Prot (2021) 2:5-12. doi: 10.1016/ j.radmp.2021.01.001

62. Sapienza LG, Nasra K, Berry R, Danesh L, Little T, Abu-Isa E. Clinical Effects of Morning and Afternoon Radiotherapy on High-Grade Gliomas. Chronobiol Int (2021) 1-10. doi: 10.1080/07420528.2021

63. Johnson K, Chang-Claude J, Critchley A-M, Kyriacou C, Lavers S, Rattay T, et al. Genetic Variants Predict Optimal Timing of Radiotherapy to Reduce Side-Effects in Breast Cancer Patients. Clin Oncol (2019) 31:9-16. doi: 10.1016/j.clon.2018.10.001

64. Noh JM, Choi DH, Park H, Huh SJ, Park W, Seol SW, et al. Comparison of Acute Skin Reaction Following Morning Versus Late Afternoon Radiotherapy in Patients With Breast Cancer Who Have Undergone Curative Surgical Resection. J Radiat Res (2014) 55:553-8. doi: 10.1093/ $\mathrm{jrr} / \mathrm{rrt141}$

65. Hsu F-M, Hou W-H, Huang C-Y, Wang C-C, Tsai C-L, Tsai Y-C, et al. Differences in Toxicity and Outcome Associated With Circadian Variations Between Patients Undergoing Daytime and Evening Radiotherapy for Prostate Adenocarcinoma. Chronobiol Int (2016) 33:210-9. doi: 10.3109/ 07420528.2015.1130049

66. Negoro H, Iizumi T, Mori Y, Matsumoto Y, Chihara I, Hoshi A, et al. Chronoradiation Therapy for Prostate Cancer: Morning Proton Beam Therapy Ameliorates Worsening Lower Urinary Tract Symptoms. J Clin Med (2020) 9:2263. doi: 10.3390/jcm9072263

67. Squire T, Buchanan G, Rangiah D, Davis I, Yip D, Chua YJ, et al. Does Chronomodulated Radiotherapy Improve Pathological Response in Locally Advanced Rectal Cancer? Chronobiol Int (2017) 34:492-503. doi: 10.1080/ 07420528.2017.1301462

68. Martinez-Nicolas A, Martinez-Madrid MJ, Almaida-Pagan PF, BonmatiCarrion M-A, Madrid JA, Rol MA. Assessing Chronotypes by Ambulatory Circadian Monitoring. Front Physiol (2019) 10:1396. doi: 10.3389/ fphys.2019.01396

69. Horne JA, Ostberg O. A Self-Assessment Questionnaire to Determine Morningness-Eveningness in Human Circadian Rhythms. Int J Chronobiol (1976) 4:97-110.

70. Roenneberg T, Wirz-Justice A, Merrow M. Life Between Clocks: Daily Temporal Patterns of Human Chronotypes. J Biol Rhythms (2003) 18:8090. doi: 10.1177/0748730402239679

71. Münch M, Kramer A. Timing Matters: New Tools for Personalized Chronomedicine and Circadian Health. Acta Physiol (2019) 227(2): e13300. doi: 10.1111/apha.13300

72. Lee K-M, Jung D-Y, Hwang H, Kim W-H, Lee J-Y, Kim T-Y, et al. Late Chronotypes are Associated With Neoadjuvant Chemotherapy-Induced
Nausea and Vomiting in Women With Breast Cancer. Chronobiol Int (2017) 34:480-91. doi: 10.1080/07420528.2017.1295978

73. Gamble KL, Berry R, Frank SJ, Young ME. Circadian Clock Control of Endocrine Factors. Nat Rev Endocrinol (2014) 10:466-75. doi: 10.1038/ nrendo. 2014.78

74. Innominato PF, Lévi FA, Bjarnason GA. Chronotherapy and the Molecular Clock: Clinical Implications in Oncology 2 . Adv Drug Deliv Rev (2010) 62:979-1001. doi: 10.1016/j.addr.2010.06.002

75. Flint MS, Baum A, Chambers WH, Jenkins FJ. Induction of DNA Damage, Alteration of DNA Repair and Transcriptional Activation by Stress Hormones. Psychoneuroendocrinology (2007) 32:470-9. doi: 10.1016/ j.psyneuen.2007.02.013

76. Flint MS, Baum A, Episcopo B, Knickelbein KZ, Liegey Dougall AJ, Chambers WH, et al. Chronic Exposure to Stress Hormones Promotes Transformation and Tumorigenicity of 3T3 Mouse Fibroblasts. Stress (2013) 16:114-21. doi: 10.3109/10253890.2012.686075

77. Flaherty RL, Owen M, Fagan-Murphy A, Intabli H, Healy D, Patel A, et al. Glucocorticoids Induce Production of Reactive Oxygen Species/Reactive Nitrogen Species and DNA Damage Through an iNOS Mediated Pathway in Breast Cancer. Breast Cancer Res (2017) 19:35. doi: 10.1186/s13058-0170823-8

78. Sephton SE. Diurnal Cortisol Rhythm as a Predictor of Breast Cancer Survival. J Natl Cancer Inst (2000) 92:994-1000. doi: 10.1093/jnci/92.12.994

79. Talib W. Melatonin and Cancer Hallmarks. Molecules (2018) 23:518. doi: 10.3390/molecules23030518

80. Majidinia M, Sadeghpour A, Mehrzadi S, Reiter RJ, Khatami N, Yousefi B. Melatonin: A Pleiotropic Molecule That Modulates DNA Damage Response and Repair Pathways. J Pineal Res (2017) 63:e12416. doi: 10.1111/jpi.12416

81. Santoro R, Marani M, Blandino G, Muti P, Strano S. Melatonin Triggers p53Ser Phosphorylation and Prevents DNA Damage Accumulation. Oncogene (2012) 31:2931-42. doi: 10.1038/onc.2011.469

82. Li Y, Li S, Zhou Y, Meng X, Zhang J-J, Xu D-P, et al. Melatonin for the Prevention and Treatment of Cancer. Oncotarget (2017) 8:39896-921. doi: 10.18632/oncotarget.16379

83. Alonso-González C, González A, Martínez-Campa C, Gómez-Arozamena J, Cos S. Melatonin Sensitizes Human Breast Cancer Cells to Ionizing Radiation by Downregulating Proteins Involved in Double-Strand DNA Break Repair. J Pineal Res (2015) 58:189-97. doi: 10.1111/jpi.12205

84. Alonso-González C, González A, Martínez-Campa C, Menéndez-Menéndez J, Gómez-Arozamena J, García-Vidal A, et al. Melatonin Enhancement of the Radiosensitivity of Human Breast Cancer Cells is Associated With the Modulation of Proteins Involved in Estrogen Biosynthesis. Cancer Lett (2016) 370:145-52. doi: 10.1016/j.canlet.2015.10.015

85. Shirazi A, Mihandoost E, Mohseni M, Ghazi-Khansari M, Rabie Mahdavi S. Radio-Protective Effects of Melatonin Against Irradiation-Induced Oxidative Damage in Rat Peripheral Blood. Phys Med (2013) 29:65-74. doi: 10.1016/j.ejmp.2011.11.007

86. Wang Y, Jin B, Ai F, Duan C, Lu Y, Dong T, et al. The Efficacy and Safety of Melatonin in Concurrent Chemotherapy or Radiotherapy for Solid Tumors: A Meta-Analysis of Randomized Controlled Trials. Cancer Chemother Pharmacol (2012) 69:1213-20. doi: 10.1007/s00280-012-1828-8

87. Lissoni P, Meregalli S, Nosetto L, Barni S, Tancini G, Fossati V, et al. Increased Survival Time in Brain Glioblastomas by a Radioneuroendocrine Strategy With Radiotherapy Plus Melatonin Compared to Radiotherapy Alone. Oncology (1996) 53:43-6. doi: 10.1159/000227533

88. Miller S, Hirota T. Pharmacological Interventions to Circadian Clocks and Their Molecular Bases. J Mol Biol (2020) 432:3498-514. doi: 10.1016/ j.jmb.2020.01.003

89. Rahman S, Wittine K, Sedić M, Markova-Car EP. Small Molecules Targeting Biological Clock; A Novel Prospective for Anti-Cancer Drugs. Molecules (2020) 25:4937. doi: 10.3390/molecules25214937

90. Sulli G, Rommel A, Wang X, Kolar MJ, Puca F, Saghatelian A, et al. Pharmacological Activation of REV-ERBs is Lethal in Cancer and Oncogene-Induced Senescence. Nature (2018) 553:351-5. doi: 10.1038/ nature 25170

91. Hirota T, Lee JW, St. John PC, Sawa M, Iwaisako K, Noguchi T, et al. Identification of Small Molecule Activators of Cryptochrome. Science (2012) 337:1094-7. doi: 10.1126/science. 1223710 
92. Tamai TK, Nakane Y, Ota W, Kobayashi A, Ishiguro M, Kadofusa N, et al. Identification of Circadian Clock Modulators From Existing Drugs. EMBO Mol Med (2018) 10(5):e8724. doi: 10.15252/emmm.201708724

93. Hirota T, Lewis WG, Liu AC, Lee JW, Schultz PG, Kay SA. A Chemical Biology Approach Reveals Period Shortening of the Mammalian Circadian Clock by Specific Inhibition of GSK-3. Proc Natl Acad Sci (2008) 105:2074651. doi: $10.1073 /$ pnas.0811410106

94. Chen Z, Yoo S-H, Park Y-S, Kim K-H, Wei S, Buhr E, et al. Identification of Diverse Modulators of Central and Peripheral Circadian Clocks by HighThroughput Chemical Screening. Proc Natl Acad Sci (2012) 109:101-6. doi: 10.1073/pnas.1118034108

95. Hirota T, Lee JW, Lewis WG, Zhang EE, Breton G, Liu X, et al. HighThroughput Chemical Screen Identifies a Novel Potent Modulator of Cellular Circadian Rhythms and Reveals CKI $\alpha$ as a Clock Regulatory Kinase. PloS Biol (2010) 8:e1000559. doi: 10.1371/journal.pbio.1000559

96. Hu JX, Gong YN, Jiang XD, Jiang L, Zhuang HQ, Meng N, et al. Local Tumor Control for Metastatic Epidural Spinal Cord Compression Following Separation Surgery With Adjuvant Cyberknife Stereotactic Radiotherapy or Image-Guided Intensity-Modulated Radiotherapy. World Neurosurg (2020) 141:e76-85. doi: 10.1016/j.wneu.2020.04.183

97. Diamant A, Heng VJ, Chatterjee A, Faria S, Bahig H, Filion E, et al. Comparing Local Control and Distant Metastasis in NSCLC Patients Between CyberKnife and Conventional SBRT. Radiother Oncol (2020) 144:201-8. doi: 10.1016/j.radonc.2020.01.017

98. Acker G, Hashemi S-M, Fuellhase J, Kluge A, Conti A, Kufeld M, et al. Efficacy and Safety of CyberKnife Radiosurgery in Elderly Patients With
Brain Metastases: A Retrospective Clinical Evaluation. Radiat Oncol (2020) 15:225. doi: 10.1186/s13014-020-01655-8

99. Wang Z, Wang J, Zhuang H, Wang P, Yuan Z. Stereotactic Body Radiation Therapy Induces Fast Tumor Control and Symptom Relief in Patients With Iliac Lymph Node Metastasis. Sci Rep (2016) 6:37987. doi: 10.1038/ srep37987

100. Cox JD, Stetz J, Pajak TF. Toxicity Criteria of the Radiation Therapy Oncology Group (RTOG) and the European Organization for Research and Treatment of Cancer (EORTC). Int J Radiat Oncol Biol Phys (1995) 31:1341-6. doi: 10.1016/0360-3016(95)00060-C

101. Schwartz LH, Litière S, de Vries E, Ford R, Gwyther S, Mandrekar S, et al. Recist 1.1-Update and Clarification: From the RECIST Committee. Eur J Cancer (2016) 62:132-7. doi: 10.1016/j.ejca.2016.03.081

Conflict of Interest: The authors declare that the research was conducted in the absence of any commercial or financial relationships that could be construed as a potential conflict of interest.

Copyright (c) 2021 Bermúdez-Guzmán, Blanco-Saborio, Ramírez-Zamora and Lovo. This is an open-access article distributed under the terms of the Creative Commons Attribution License (CC BY). The use, distribution or reproduction in other forums is permitted, provided the original author(s) and the copyright owner(s) are credited and that the original publication in this journal is cited, in accordance with accepted academic practice. No use, distribution or reproduction is permitted which does not comply with these terms. 